\title{
Romanian complex data center for dense seismic network
}

\author{
Cristian Neagoe ${ }^{1,{ }^{\star}}$, Liviu Marius Manea ${ }^{1}$, Constantin Ionescu ${ }^{1}$
}

${ }^{1}$ National Institute for Earth Physics, Bucharest, Romania

\author{
Article history \\ Received May 5, 2010; accepted September 10, 2010. \\ Subject classification: \\ Earthquakes, Monitoring, Seismology, Algorithms, Data acquisition.
}

\section{ABSTRACT}

In 2002, the National Institute for Earth Physics started the development of its own real-time digital seismic network. This now consists of 86 seismic stations, of which 32 are broad-band sensors, 52 stations are equipped with short-period sensors, and two seismic arrays, all of which transmit data in real time to the National Data Center (NDC) and the Eforie Nord (EFOR) seismic observatory. EFOR is the back-up for the $N D C$, and it is also a monitoring center for Black Sea tsunamis. The seismic stations are equipped with Quanterra Q330 and K2 digitizers, broad-band seismometers (STS2, CMG40T, CMG 3ESP, CMG3T) and Episensor Kinemetrics acceleration sensors $( \pm 2 g)$. SeedLink is a part of Seiscomp2.5 and Antelope, which are the software packages used for data acquisition in real time and data exchange. Communication from the digital seismic stations to the NDC in Bucharest and EFOR is assured by five providers (GPRS, VPN, satellite, radio and internet). AntelopeTM 4.11 is used for acquisition and data processing at these two data centers for the reception and processing of the data, which runs on two workstations: one for real-time processing and the other for offline processing. A Seiscomp 3 server works as the back-up for the Antelope 4.11. This acquisition and analysis systems for the seismic data produce information about the local and global parameters of earthquakes. In addition, Antelope is used for manual processing (e.g. association events, creation of a database, sending seismic bulletins, and calculation of magnitude and peak ground acceleration and velocity), generation of ShakeMap products, and interactions with global data centers. The NDC has developed tools to make all of this information easily available across the internet, and also to lay the grounds for a more modular and flexible development environment. This will enable centralizing of the data from software such as Antelope, which is using a dedicated database system (Datascope; a database system based on text files), to the more general-purpose database, MySQL. This acts like a hub between the different acquisition and analysis systems used at the $N D C$, while also providing better connectivity at no expense to security. Mirroring certain data to MySQL also allows the NDC to easily share information with the public, via the new application that is being developed, and also to mix in data collected from the public (e.g. information about the damage after an earthquake, which can be used to produce macroseismic intensity indices that are then stored in the database and also made available via the web application). For internal use, there is also a web application that uses the data stored in the database to display earthquake information, like location, magnitude and depth, in semi real time, thus aiding the personnel on duty. Another use for the data collected is to create and maintain contact lists to which the datacenter sends notifications (SMS and email), based on the parameters of an earthquake. For the future development, one of the NDC plans is to develop the means to cross-check the data generated between the different acquisition and analysis systems (e.g. comparing data generated by Antelope with data generated by Seiscomp).

\section{Introduction}

The National Institute for Earth Physics (NIEP) operates a real-time seismic network that is designed to monitor the seismic activity in the Romania territory, which is dominated by the Vrancea intermediate-depth (60-200 $\mathrm{km}$ ) earthquakes.

The ability to reduce the impact of earthquakes on society depends on the existence of a large amount of highquality observational data. The development in the last few years of the seismic network and of an advanced acquisition system are essential factors to achieve this goal.

Starting in 2002, the modernization of the Romania seismic network was based on the installation of new seismic stations operating in real time. This network consists of digital seismic stations that are equipped with acceleration sensors (EpiSensor) and velocity sensors (broad-band: STS2, CMG3ESP, KS2000, CMG40-T; or short period: MP, SH-1, S13, Mark Product).

\section{Real-time data system}

The real-time digital seismic network consists of 86 seismic stations with three components, including two arrays: BURAR with 12 elements and PLOR with 7 elements. All of the data recorded by this network are transmitted in real time to the NIEP for automatic data processing, analysis and dissemination. The seismic station locations and equipment characteristics for the real-time Romania Seismic Network are given in Table 1. 


\begin{tabular}{|c|c|c|c|c|}
\hline Station code & $\begin{array}{l}\text { Latitude } \\
\qquad\left({ }^{\circ} \mathbf{N}\right)\end{array}$ & $\begin{array}{c}\text { Longitude } \\
\left({ }^{\circ} \mathbf{E}\right)\end{array}$ & $\begin{array}{l}\text { Elevation } \\
\quad(\mathbf{m})\end{array}$ & Recording equipment type \\
\hline ARCR & 47.085 & 24.353 & 385 & Q330 + MARMOT, STS2 + Episensor \\
\hline ARR & 45.365 & 24.633 & 871 & Q330, CMG3ESP + Episensor \\
\hline AMRR & 44.610 & 27.335 & 67 & Q330 + MARMOT S13, SH1 + Episensor \\
\hline BANR & 45.382 & 21.137 & 80 & Q330 + MARMOT, KS200 + Episensor \\
\hline BAPR & 44.405 & 26.119 & 103 & K2 Digitizer, Mark + Episensor \\
\hline BMR & 47.672 & 23.496 & 294 & Q330, CMG40T+ Episensor \\
\hline BSTR & 44.445 & 26.098 & 125 & K2 Digitizer, Mark + Episensor \\
\hline BTMR & 44.437 & 26.106 & 140 & K2 Digitizer, S13, SH1 + Episensor \\
\hline BUC & 44.410 & 26.093 & 82 & K2 Digitizer, Mark + Episensor \\
\hline BUC1 & 44.347 & 26.028 & 77 & K2 Digitizer, Mark + Episensor \\
\hline BURAR & 47.644 & 25.200 & 1216 & 9 SP - GS21, 1 BB - KS5400, 5 CMG40T \\
\hline BVCR & 44.430 & 26.101 & 112 & K2 Digitizer, Mark + Episensor \\
\hline $\mathrm{BZS}$ & 45.618 & 21.640 & 260 & Q330, STS2 + Episensor \\
\hline CFR & 45.178 & 28.136 & 52 & Q330 + MARMOT, CMG40T + Episensor \\
\hline CIOR & 44.448 & 25.879 & 138 & Q330 + MARMOT, Mark + Episensor \\
\hline CJR & 46.713 & 23.598 & 750 & Q330 + MARMOT, CMG3ESP+ Episensor \\
\hline CNCR & 44.43 & 26.61 & 105 & K2 Digitizer, + Episensor \\
\hline CRAR & 44.325 & 23.799 & 125 & Q330, CMG3ESP + Episensor \\
\hline CVD & 44.351 & 28.039 & 153 & Q330, Mark + Episensor \\
\hline CVD1 & 44.320 & 28.062 & 50 & Q330, CMG40T + Episensor \\
\hline DEV & 45.887 & 22.898 & 250 & Q330, CMG40T + Episensor \\
\hline DOPR & 45.967 & 25.388 & 526 & Q330 + MARMOT, STS2 + Episensor \\
\hline DRGR & 46.791 & 22.711 & 921 & Q330, KS2000 + Episensor \\
\hline EFOR & 44.075 & 28.632 & 103 & Q330 + MARMOT, Ranger + Episensor \\
\hline GIUM & 45.485 & 28.208 & 106 & K2 Digitizer ,CMG40T + Episensor \\
\hline GRER & 45.380 & 26.974 & 276 & Q330 + MARMOT, S13, SH1 + Episensor \\
\hline GHRR & 46.060 & 27.408 & 212 & Q330 + MARMOT, CMG3ESP + Episensor \\
\hline GOLR & 44.843 & 24.981 & 301 & Q330 + MARMOT, S13, SH1 + Episensor \\
\hline GZR & 45.393 & 22.776 & 850 & Q330 + MARMOT, STS2 + Episensor \\
\hline HARR & 44.689 & 27.930 & 118 & Q330 + MARMOT, S13 + Episensor \\
\hline HUMR & 44.528 & 24.980 & 247 & Q330 + MARMOT, CMG40T + Episensor \\
\hline IAS & 47.193 & 27.553 & 160 & Q330 + MARMOT, KS2000 + Episensor \\
\hline INCR & 44.441 & 26.161 & 88 & Q330, MARK + Episensor \\
\hline ISR & 45.118 & 26.543 & 750 & Q330 + MARMOT, CMG3ESP + Episensor \\
\hline KIS & 46.997 & 28.817 & 185 & Q330, CMG40T + Episensor \\
\hline LEOM & 46.473 & 28.246 & 52 & K2 Digitizer, CMG40T + Episensor \\
\hline LOT & 45.446 & 23.769 & 1240 & Q330 + MARMOT, STS2 + Episensor \\
\hline MANR & 43.816 & 28.587 & 71.9 & Q330 + MARMOT, MARK + Episensor \\
\hline MDB & 46.149 & 24.376 & 375 & K2 Digitizer, MARK + Episensor \\
\hline MILM & 46.918 & 28.812 & 64 & Q330 + MARMOT, STS2 + Episensor \\
\hline MLR & 45.490 & 25.945 & 1360 & Q330, STS2 + Episensor \\
\hline MSAB & 44.089 & 27.826 & 124 & Q330, CMG40T + Episensor \\
\hline MTUR & 45.234 & 25.073 & 1018 & Q330 + MARMOT, S13 + Episensor \\
\hline ODBI & 45.763 & 27.055 & 181 & Q330, RANGER + Episensor \\
\hline
\end{tabular}




\begin{tabular}{|c|c|c|c|c|}
\hline Station code & $\begin{array}{c}\text { Latitude } \\
\qquad\left({ }^{\circ} \mathbf{N}\right)\end{array}$ & $\begin{array}{c}\text { Longitude } \\
\left({ }^{\circ} \mathbf{E}\right)\end{array}$ & $\begin{array}{l}\text { Elevation } \\
(\mathrm{m})\end{array}$ & Recording equipment type \\
\hline PETR & 45.723 & 27.231 & 86 & K2 Digitizer, KS2000+ Episensor \\
\hline PGOR & 44.919 & 26.976 & 98 & Q330 + MARMOT, S13, SH1 + Episensor \\
\hline PLAR & 44.914 & 26.027 & 146 & Q330 + MARMOT, MARK + Episensor \\
\hline PLSP4 & 45.851 & 26.649 & 672 & Q330, GS21 \\
\hline PLOR & 45.851 & 26.649 & 657 & Q330, STS2, 6 CMG40T + 4 Episensor \\
\hline PRAR & 47.361 & 26.227 & 451 & Q330 + MARMOT, MARK + Episensor \\
\hline RMGR & 44.662 & 22.692 & 113 & Q330 + MARMOT, MARK + Episensor \\
\hline RMVG & 45.036 & 24.284 & 260 & K2 Digitizer, MARK + Episensor \\
\hline SECR & 45.035 & 26.067 & 417 & K2 Digitizer, S13, SH1 + Episensor \\
\hline SIRR & 46.265 & 21.663 & 480 & Q330 + MARMOT, CMG40T + Episensor \\
\hline SIBR & 45.809 & 24.175 & 463 & Q330, S13 + Episensor \\
\hline SRE & 44.660 & 23.203 & 335 & Q330 + MARMOT, MARK + Episensor \\
\hline SORM & 48.135 & 28.351 & 64 & Q330, CMG40T + Episensor \\
\hline SULR & 44.677 & 26.252 & 73 & Q330, KS2000 + Episensor \\
\hline TESR & 46.511 & 26.648 & 372 & Q330 + MARMOT, STS2 + Episensor \\
\hline TIM & 45.736 & 21.221 & 88 & K2 Digitizer, S13, SH1 + Episensor \\
\hline TLB & 44.585 & 28.041 & 60 & Q330, CMG40T + Episensor \\
\hline TNR & 45.652 & 24.273 & 519 & Q330, S13 \\
\hline TIRR & 44.458 & 28.412 & 77 & PS6-24, STS2 + Episensor \\
\hline TLCR & 45.186 & 28.815 & 73 & Q330 + MARMOT, MARK + Episensor \\
\hline VOIR & 45.437 & 25.049 & 969 & Q330, STS2 + Episensor \\
\hline VRI & 45.865 & 26.727 & 472 & Q330, STS2 + Episensor \\
\hline ZIMR & 43.657 & 25.365 & 74 & Q330, Ranger + Episensor \\
\hline
\end{tabular}

Table 1 (continues from previous page). Seismic stations and instrumentation. All of the stations listed have real-time data transfer modes.

The remote seismological stations have three-component seismometers for weak motion and three-component accelerometers for strong motion.

In cooperation with the Kishinev Institute of Geophysics and Seismology, Republic of Moldova, three seismic stations have been installed in the Republic of Moldova. These seismic stations were installed at Leova (LEOM), Giurgiulesti (GIUM) and Milestii Mici (MILM). Also, in collaboration with the same institute, two more seismic stations have been installed in Kishinev (KIS) and Soroca (SORM).

All of the data from the seismic stations installed in the Republic of Moldova territory are received in real time at the NIEP Data Centre using seedlink connections.

The primary goal of the real-time seismic network is to provide earthquake parameters from more broad-band stations with a high dynamic range, for more rapid and accurate computation of the locations and magnitudes of earthquakes. The Seedlink and Antelope ${ }^{\mathrm{TM}}$ program packages are used for this real-time data acquisition and exchange.

The real-time digital seismic network developed by the
NIEP is illustrated in Figure 1. The near-future strategies include installing additional broad-band stations in the central and western parts of Romania, and another 40 strong-motion stations in Bucharest city.

A completely automated Antelope seismological system [BRTT 2011] (Figure 2) is run at the Data Center in Magurele. The Antelope data acquisition and processing software is run on two workstations for real-time processing and postprocessing. The Antelope real-time system provides automatic event detection, arrival picking, event location, and magnitude calculation. It also provides graphical displays and automatic location within near real time after a local, regional or teleseismic event has occurred [Neagoe and Ionescu 2009].

SeisComP 3 is another automated system that is run at the NIEP and which provides the following features: data acquisition, data quality control, real-time data exchange and processing, network status monitoring, issuing event alerts, waveform archiving and data distribution, automatic event detection and location, easy access to relevant information about stations, waveforms, and recent earthquakes [SeisComP3.org 2011a, 2011b] (Figure 3). 


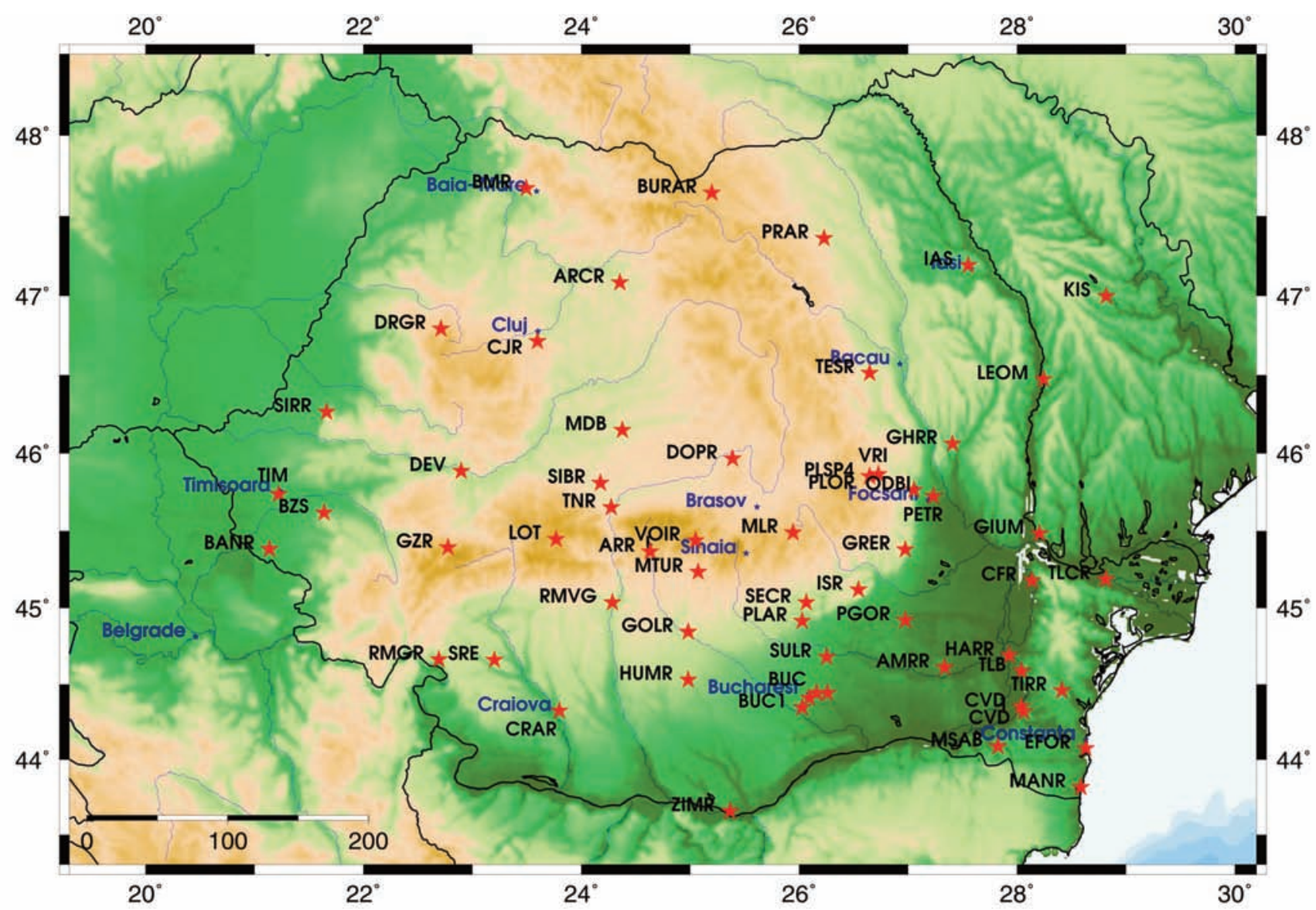

Figure 1. The real-time digital seismic network developed by the NIEP.

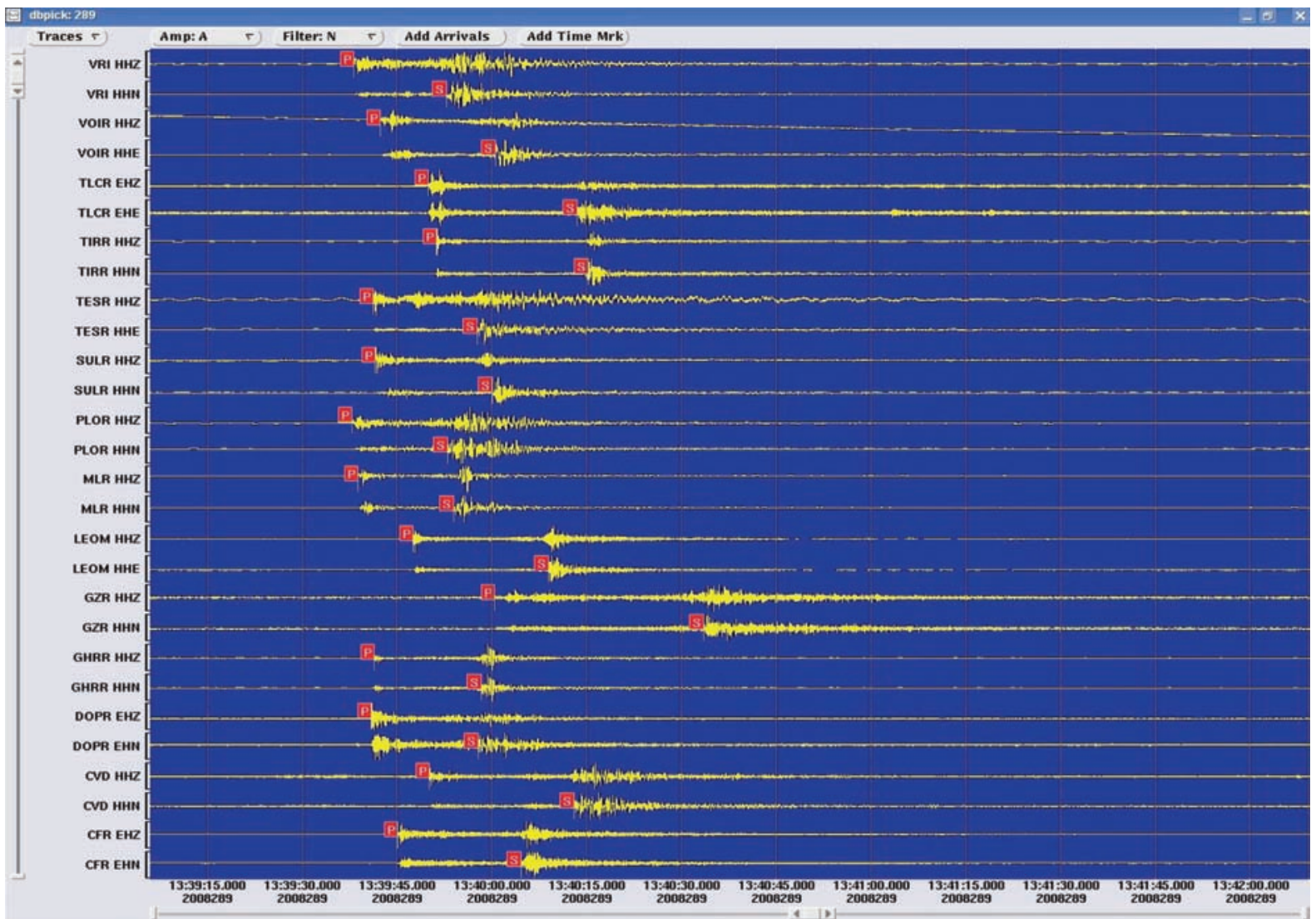

Figure 2. Example of the manual data-processing with Antelope software. 

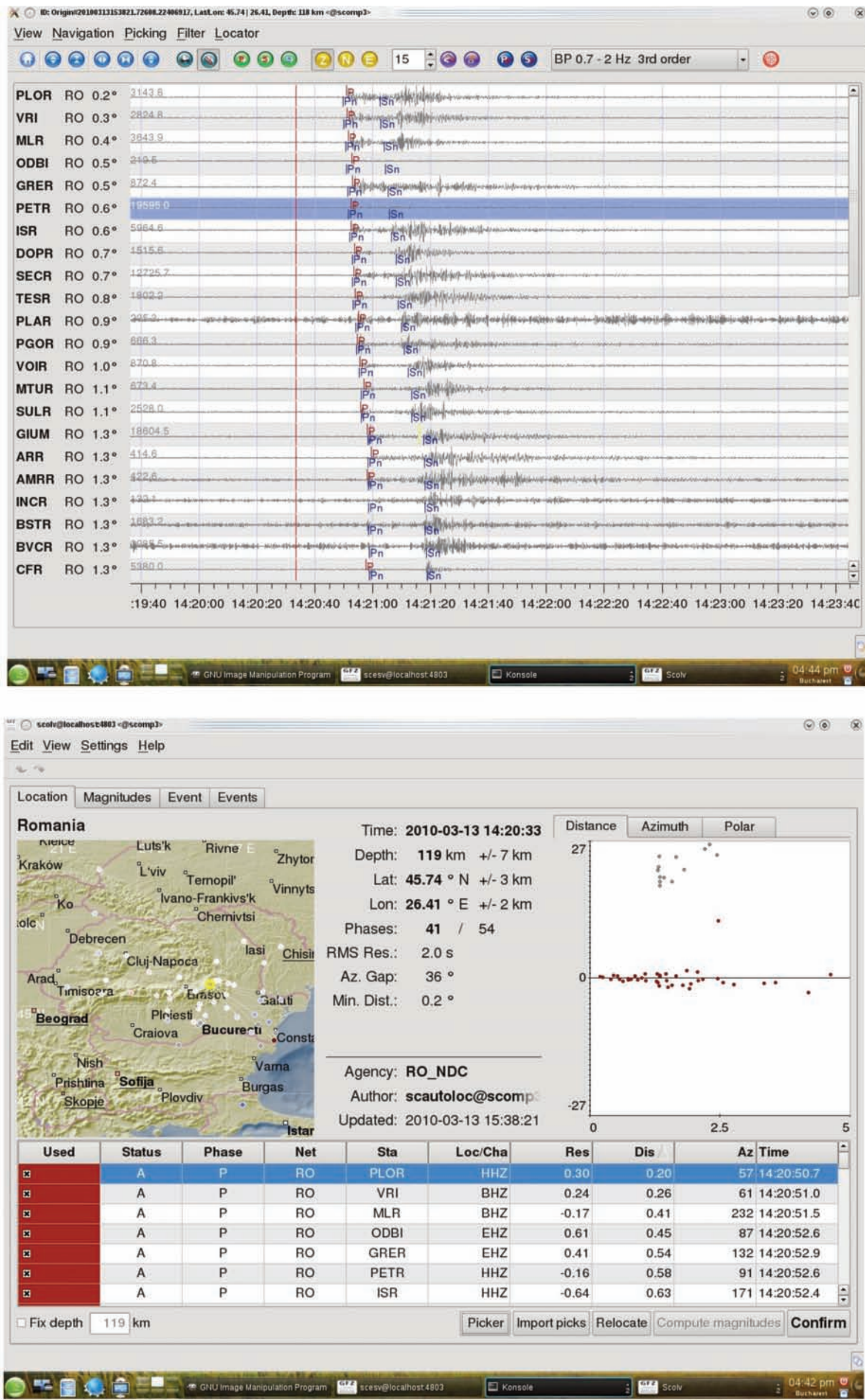

Figure 3. Automatic detection (top panel) and seismic data processing (bottom panel) using the SeiscomP 3 software. 


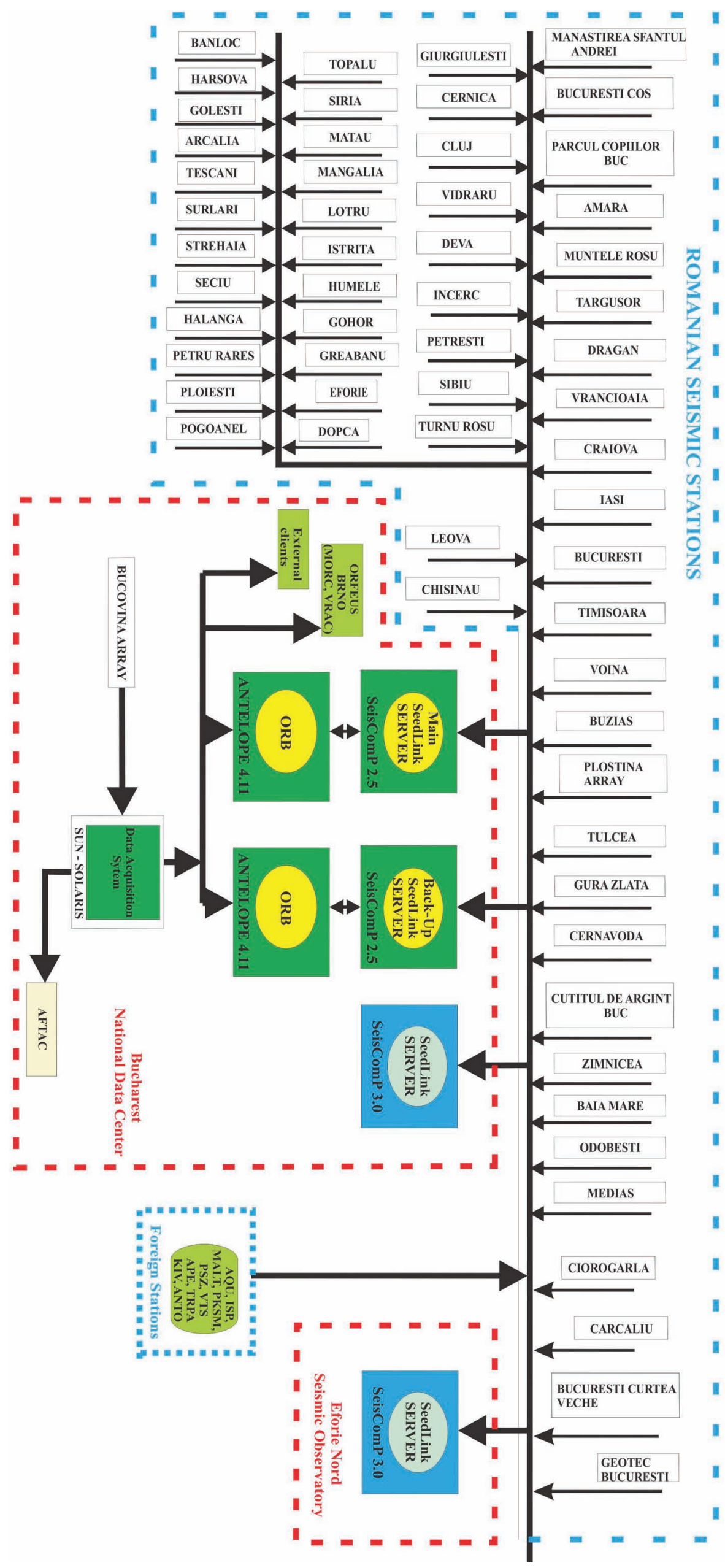


ROMANIAN DENSE SEISMIC NETWORK

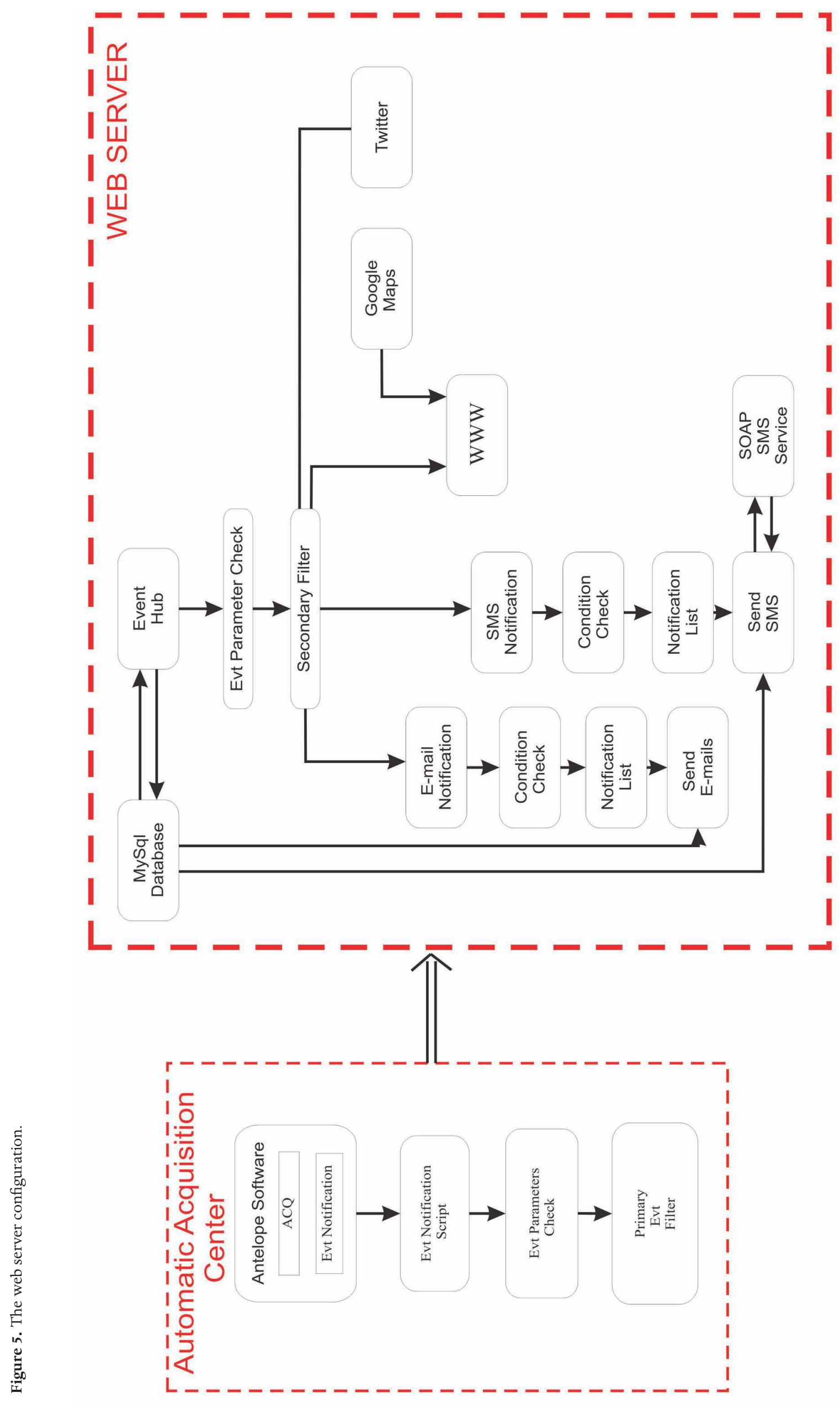


The Romania Seismic Network exchanges data with international organizations like ORFEUS and IRIS and with data centers from other European countries via the internet. The data provided consist of near-real-time waveform data from six broad-band stations: Iasi, Dragan (DRGR), Craiova (CRAR), Bucharest (BUC1), Vrincioaia (VRI), Muntele Rosu (MLR) and the Bucovina (BURAR) array (Figure 4).

\section{Real-time analysis}

Both the acquisition and analysis of seismic data systems produces information relating to the local and global parameters of earthquakes. In addition, Antelope is used for manual processing (e.g. association events, magnitude computation, database, sending seismic bulletins, calculation of peak ground acceleration and velocity), generating ShakeMap products, and interacting with international data centers.

To make all of this information easily available across the internet, and also to lay the grounds for a more modular and flexible development environment, the NDC has developed tools to enable the centralizing of the seismological data.

As Antelope is using a dedicated database system (Datascope, a database system based on text files), we have moved the data to a more general-purpose database, MySQL, which acts like a hub between the different acquisition systems used in the NDC. The MySQL database also provides better connectivity at no expense to security (Figure 5).

Mirroring certain data to MySQL also allows the NDC to easily share information with the public via the new application that is being developed, and also to mix in data collected from the public (e.g. information about damage after an earthquake that can be used to produce macroseismic intensity indices, which are then stored in the database and also made available via the web application). For internal use, there is also a web application that uses the data stored in the database to display earthquake information in semi real time, like location, magnitude and depth.

Another use of the data collected is to create and maintain contact lists to which the data center sends notifications (SMS and email) based on earthquake parameters.

\section{Future developments}

The Romania Seismic Network will be enlarged by the installation of new stations that will provide seismic data in real time to the NDC. The up-graded network will provide new data for site effect studies and microzonation purposes, and it will be used for developing and evaluatiing shake maps for all of the country, and in particular in the Bucharest area.

Among the various aspects of the future development, the NDC plans to develop the means to cross-check the data generated between the different acquisition and analysis systems (e.g. comparing data generated by Antelope with data generated by Seiscomp).

\section{References}

BRTT (2011). Evolution of the Commercial ANTELOPE Software; http://www.brtt.com/docs/evolution.pdf.

Neagoe, C. and C. Ionescu (2009). Toward a dense real-time seismic network, Romanian Rep. Phys., 61, 359-366.

SeisComP3.org (2011a). Introduction and scope; http:/ / www. seiscomp3.org/wiki/doc/introduction-and-scope.

SeisComP3.org (2011b). Software architecture. http:/ / www. seiscomp3.org/wiki/doc/software-architecture/.

\footnotetext{
${ }^{\star}$ Corresponding author: Cristian Neagoe, National Institute for Earth Physics, Bucharest, Romania; e-mail: cristian.neagoe@infp.ro.

C 2011 by the Istituto Nazionale di Geofisica e Vulcanologia. All rights reserved.
} 